\title{
Role of pre-operative transthoracic echocardiography in predicting post-operative atrial fibrillation after cardiac surgery: a systematic review of the literature and meta-analysis
}

Citation for published version (APA):

Kawczynski, M. J., Gilbers, M., Van de Walle, S., Schalla, S., Crijns, H. J., Maessen, J. G., Schotten, U., Maesen, B., \& Bidar, E. (2021). Role of pre-operative transthoracic echocardiography in predicting postoperative atrial fibrillation after cardiac surgery: a systematic review of the literature and meta-analysis. EP Europace, 23(11), 1731-1743. https://doi.org/10.1093/europace/euab095

Document status and date:

Published: 01/11/2021

DOI:

10.1093/europace/euab095

Document Version:

Publisher's PDF, also known as Version of record

Document license:

Taverne

Please check the document version of this publication:

- A submitted manuscript is the version of the article upon submission and before peer-review. There can be important differences between the submitted version and the official published version of record. People interested in the research are advised to contact the author for the final version of the publication, or visit the $\mathrm{DOI}$ to the publisher's website.

- The final author version and the galley proof are versions of the publication after peer review.

- The final published version features the final layout of the paper including the volume, issue and page numbers.

Link to publication

\footnotetext{
General rights rights.

- You may freely distribute the URL identifying the publication in the public portal. please follow below link for the End User Agreement:

www.umlib.nl/taverne-license

Take down policy

If you believe that this document breaches copyright please contact us at:

repository@maastrichtuniversity.nl

providing details and we will investigate your claim.
}

Copyright and moral rights for the publications made accessible in the public portal are retained by the authors and/or other copyright owners and it is a condition of accessing publications that users recognise and abide by the legal requirements associated with these

- Users may download and print one copy of any publication from the public portal for the purpose of private study or research.

- You may not further distribute the material or use it for any profit-making activity or commercial gain

If the publication is distributed under the terms of Article 25fa of the Dutch Copyright Act, indicated by the "Taverne" license above,

Download date: 26 Apr. 2023 


\title{
Role of pre-operative transthoracic echocardiography in predicting post-operative atrial fibrillation after cardiac surgery: a systematic review of the literature and meta-analysis
}

\author{
Michal J. Kawczynski (1) ${ }^{1,2}$, Martijn Gilbers ${ }^{1,2}$, Sophie Van De Walle \\ Simon Schalla ${ }^{3,4,5}$, Harry J. Crijns ${ }^{3,4}$, Jos G. Maessen ${ }^{1,2}$, Ulrich Schotten $\mathbb{1}^{2}$, \\ Bart Maesen $^{1,2}$, and Elham Bidar ${ }^{1,2 *}$
}

\begin{abstract}
${ }^{1}$ Department of Cardiothoracic Surgery, Heart and Vascular Centre Maastricht University Medical Centre, Professor Debyelaan 25, 6229 HX Maastricht, The Netherlands; ${ }^{2}$ Department of Physiology, Maastricht University, Maastricht, The Netherlands; ${ }^{3}$ Cardiovascular Research Institute Maastricht (CARIM), Maastricht, The Netherlands;

${ }^{4}$ Department of Cardiology, Heart and Vascular Centre, Maastricht University Medical Centre, Maastricht, The Netherlands; and ${ }^{5}$ Department of Radiology, Maastricht University Medical Centre, Maastricht, The Netherlands
\end{abstract}

Received 20 November 2020; editorial decision 21 March 2021; accepted 30 March 2021; online publish-ahead-of-print 17 May 2021

\begin{abstract}
Aims
This systematic review and meta-analysis aims to evaluate the role of pre-operative transthoracic echocardiography in predicting post-operative atrial fibrillation (POAF) after cardiac surgery.

Methods and

results

Electronic databases were searched for studies reporting on pre-operative echocardiographic predictors of POAF in PubMed, Cochrane library, and Embase. A meta-analysis of echocardiographic predictors of POAF that were identified by at least five different publications was performed. Forty-three publications were included in this systematic review. Echocardiographic predictors for POAF included surrogate parameters for total atrial conduction time (TACT), structural cardiac changes, and functional disturbances. Meta-analysis showed that prolonged pre-operative PA-TDI interval [5 studies, Cohen's $d=1.4,95 \%$ confidence interval (Cl) 0.9-1.9], increased left atrial volume indexed for body surface area (LAVI) (23 studies, Cohen's $d=0.8,95 \% \mathrm{Cl} 0.6-1.0)$, and reduced peak atrial longitudinal strain (PALS) (5 studies, Cohen's $d=1.4,95 \% \mathrm{Cl} 1.0-1.8)$, were associated with POAF incidence. Left atrial volume indexed for body surface was the most important predicting factor in patients without a history of AF. These parameters remained important predictors of POAF in heterogeneous populations with variable age and comorbidities such as coronary artery disease and valvular disease.
\end{abstract}
Conclusion This meta-analysis shows that increased TACT, increased LAVI, and reduced PALS are valuable parameters for pre- dicting POAF in the early post-operative phase in a large variety of patients.

Keywords

Post-operative atrial fibrillation - Echocardiography - Cardiac surgery • Meta-analysis

\section{Introduction}

Post-operative atrial fibrillation (POAF) is the most common complication after cardiac surgery and up to $30 \%$ of patients without a history of AF develops POAF. ${ }^{1,2}$ Historically POAF has been considered a transient arrhythmia resulting from triggers in the surgical aftermath. However, more recently POAF has been identified as an independent predictor of late AF development, early and long-term post-operative stroke, and increased all-cause mortality in the years following cardiac surgery, suggesting it may be an expression of an

* Corresponding author. Tel: +31 43387 2727. E-mail address: elham.bidar@mumc.nl

Published on behalf of the European Society of Cardiology. All rights reserved. (c) The Author(s) 2021. For permissions, please email: journals.permissions@oup.com. 


\section{What's new?}

- Increased preoperative total atrial conduction time (TACT, measured as PA- TDI interval), increased left atrial volume indexed for body surface area ( $\mathrm{LAVI})$, and reduced preoperative longitudinal strain (PALS), have a strong correlation with POAF incidence.

- These variables, which can be effectively measured by conventional bedside TTE, depict electrophysiological, structural, and functional cardiac changes associated with an arrhythmogenic substrate for POAF.

- Implementing measurements of preoperative TACT (measured as PA-TDI interval), LAVI, and PALS in the standard preoperative care might help to identify patients at risk for POAF.

- Using these parameters in the preoperative setting could result in a paradigm switch from "risk-factor-based" predictive models to "substrate-based" predictive models for POAF.

ingrained substrate..$^{2-4}$ In addition, identification of pre-existing clinical risk factors for POAF such as advanced age, hypertension, congestive heart failure, and its high incidence rate in valvular heart disease has emphasized the role of a pre-existing arrhythmogenic basis for POAF development. ${ }^{5}$ Transthoracic echocardiography (TTE) is used to assess cardiac function in the pre-operative workup and several anatomical and functional echocardiographic parameters have been identified to be associated with POAF development. ${ }^{6,7}$ These findings suggest that TTE has an important role in determining the pathophysiological changes, which may have already taken place in the atria prior to clinical manifestation of AF. In addition, novel echocardiographic techniques, such as strain analysis or the analysis of the atrial electrical conduction, offer new perspectives for quantification of the arrhythmogenic substrate in POAF patients. ${ }^{8-12}$. This systematic review aims to evaluate and classify these important echocardiographic parameters predicting POAF.

\section{Methods}

\section{Literature search}

For this systematic review, the 2009 PRISMA guidelines were followed. ${ }^{13}$ In March 2020, a systematic literature search was conducted in PubMed, Cochrane database, and Embase (Supplementary material online, Table S1). Citation tracking was performed to identify additional publications.

\section{Study selection}

All identified studies were screened on their titles and abstracts. Two investigators were involved in identifying studies meeting criteria for inclusion (M.J.K. and M.G.). Studies with hybrid or catheter ablation as major intervention, studies not published in English, or studies without description of pre-operative echocardiographic workup and post-operative monitoring for POAF were excluded after screening the titles and abstracts. Full texts of the remaining articles were screened. The inclusion criteria for the systematic review were a pre-operative TTE evaluation of the cardiac function, cardiac surgery, and post-operative monitoring for POAF.

\section{Quality assessment}

The Downs and Black tool for quality assessment in non-randomized clinical trials was used to assess the quality of the studies included in the systematic review. ${ }^{14}$ Additionally, description of TTE protocol and monitoring for POAF were added to the quality assessment.

\section{Study outcomes}

Primary outcomes were all pre-operative TTE parameters associated with the occurrence of POAF.

\section{Statistical analysis}

For echocardiographic variables that were identified by a minimum number of five publications as an independent predictor of POAF in a multivariable analysis, a meta-analysis was performed. A minimum amount of five publications was set to assess the effect of echocardiographic variables that showed a strong correlation with POAF.

Meta-analysis for continuous variables was performed to define the pooled standardized mean differences (SMD). To assess the SMD of the variables, Cohen's $d$ was calculated. The following cut-offs for the interpretation of the SMD were selected: $0<$ Cohen's $d<0.2=$ no effect, $0.2 \leq$ Cohen's $d<0.5=$ small effect, $0.5 \leq$ Cohen's $d<0.8=$ intermediate effect, Cohen's $d \geq 0.8=$ large effect. For the variables that were measured on the binary or categorical scale, a meta-analysis for binary groups was performed. Pooled results of the meta-analysis were visualized in a forest plot along with the standard deviations. Heterogeneity was assessed with the Cochrane Q-test and $P^{2}$ statistics with a significant cutoff value of $P<0.10$ and $I^{2}>50 \%$, respectively. To explore the patterns of heterogeneity, a Leave-one-out analysis or a Graphic Display of Heterogeneity (GOSH) plot was performed. ${ }^{15}$ Subgroup analysis and meta-regression were performed to examine the between-study differences that might contribute to overall heterogeneity and different patterns of effect size distribution. The subgroups were defined based on the suspected contributors to between-study differences (patient characteristics, outcome measures and definitions, or interventions).

The publication bias was assessed in a funnel plot and by performing the Egger's test with a $P$-value $<0.10$ regarded as statistically significant. ${ }^{16}$ Significant publication bias was explored using a Duval and Tweedie's trim-and-fill procedure to estimate the actual effect size. ${ }^{17}$ All statistical values were computed with a $95 \%$ confidence interval $(\mathrm{Cl})$ in randomeffects models. The two-tailed $P$-value cut-off for statistical significance was set at $<0.05$. All statistical models were created in 'Rstudio Version 1.2.1335' by using the 'meta', 'metafor', and 'dmetar' packages available for performing meta-analyses. ${ }^{18,19}$

\section{Results}

\section{Study selection}

After searching PubMed, Cochrane library, and Embase, 2531 citations were retrieved. After excluding 683 titles (duplicates, review articles, case reports, conference publications, and editorials), 1848 articles were screened for title and abstract according to the inclusion and exclusion criteria. We identified 94 studies that were eligible for the systematic review. After full-text evaluation, we excluded 51 articles based on various reasons (Supplementary material online, Table S2). Eventually, 43 publications were included in the systematic review and 23 studies in the meta-analyses of different echocardiographic variables. The summary of studies included in the meta-analysis is provided in Supplementary material online, Table S3. Figure 1 depicts the study selection process for this systematic review. 


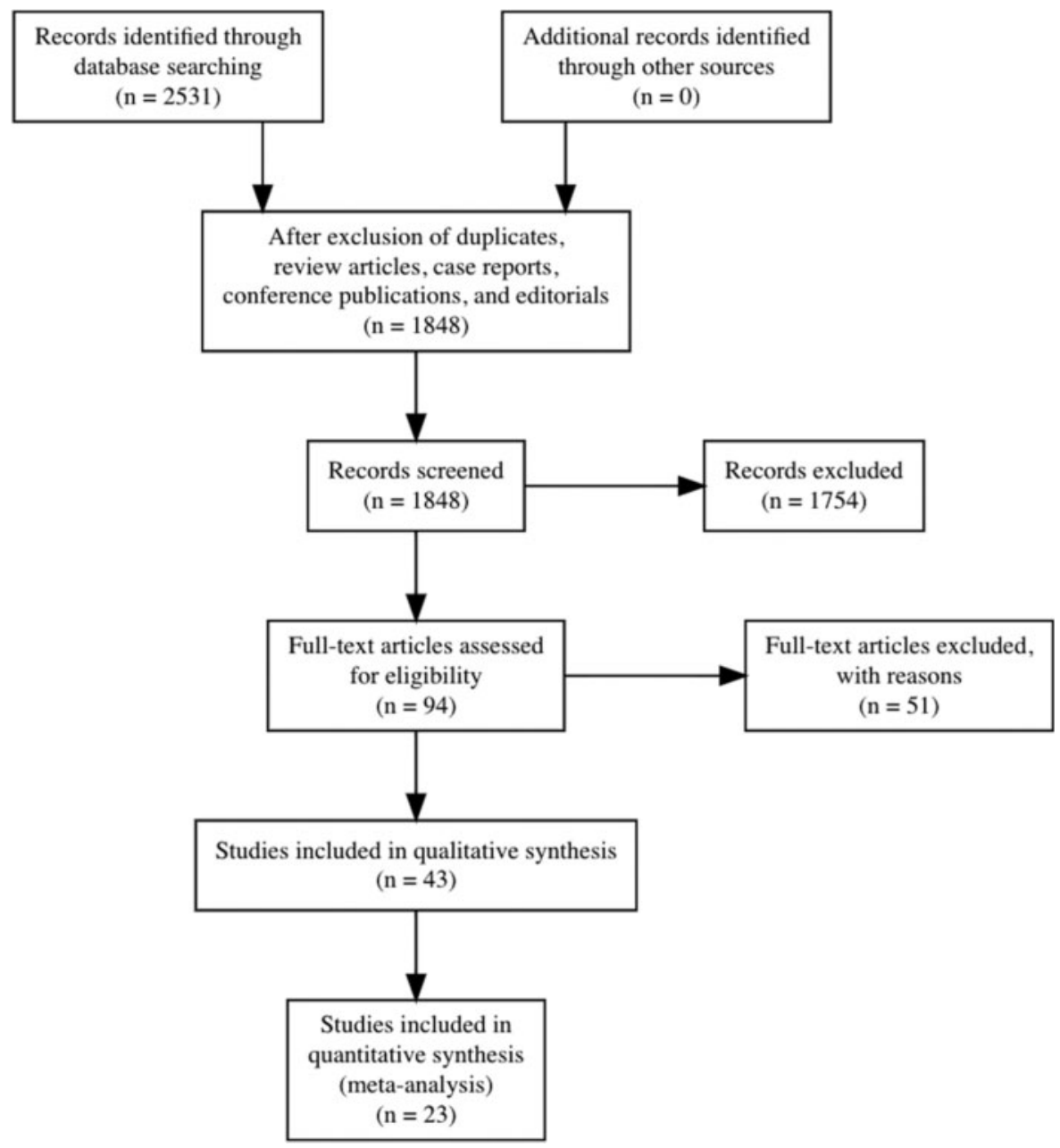

Figure I Study selection diagram.

\section{Quality of studies}

The quality of the studies included in the systematic review was high (Supplementary material online, Table S4). Objectives, outcomes, and main findings were clearly described in all studies. Most of the studies provided clear descriptions of imaging protocols, interventions, monitoring for POAF, and statistical analysis in the methods section. All studies clearly described whether patients with prior history of AF were included. In almost all studies, multivariable regression analysis was performed to adjust for potential confounders.

\section{Study outcomes}

\section{Total atrial conduction time}

Six studies found that a prolonged pre-operative total atrial conduction time (TACT), measured as atrial electromechanical interval (AEMI) or PA-TDI (interval between P-wave onset to peak A-wave measured with tissue Doppler imaging), was related to a higher incidence of POAF (Table 1). ${ }^{20-25}$

Meta-analysis for PA-TDI

Five studies were included in the continuous variables meta-analysis of PA-TDI using a random effects model (Figure 2). ${ }^{20-24}$ One study was excluded from the meta-analysis, since the TACT was measured as the time interval from the start of the P-wave to the beginning of the A-wave, instead of the peak A-wave, which is a different technique compared to earlier mentioned studies. ${ }^{25}$ Figure $5 \mathrm{~A}$ demonstrates the average PA-TDI values calculated from the studies included in the meta-analysis. Patients developing POAF showed prolonged PA-TDI compared to patients without POAF (mean 151.3 vs. $127.8 \mathrm{~ms}$, respectively). The cumulative Cohen's $d$ obtained from the meta-analysis was $1.4(0.9-1.9)$. The heterogeneity of the model was high $I^{2}=78 \%$. Leave-one-out analysis for the meta-analysis of PA-TDI showed that omitting one study would reduce the $l^{2}$ to $40 \%$ without heavily influencing the overall SMD (1.2, 95\% Cl: 0.9-1.5) (Supplementary material online, Figure S1). ${ }^{24}$

\section{Structural and functional parameters}

Data on structural and functional risk factors and correlation with POAF are presented inTables 2 and $3 .^{6-11,20-53}$ Several studies identified parameters representing left atrial (LA) structural remodelling, such as LA volume (LAV), LA diameter (LAD), LA area, and LA size, to be associated with POAF. ${ }^{26,28-31,34-36,50}$, Also, diastolic dysfunction, reduced $L A$ ejection fraction (LAEF), and reduced left 
Table I Pre-operative electrophysiological disturbances identified by echocardiography as independent predictors of POAF

\begin{tabular}{|c|c|c|c|c|c|c|c|c|}
\hline Study & $\begin{array}{l}\text { Number of } \\
\text { participants }\end{array}$ & $\begin{array}{l}\text { Timing of } \\
\text { pre-operative } \\
\text { TTE }\end{array}$ & $\begin{array}{l}\text { Type of } \\
\text { surgery }\end{array}$ & POAF \% & $\begin{array}{l}\text { Predictors } \\
\text { of POAF }\end{array}$ & $\begin{array}{l}\text { Statistical value } \\
\qquad(95 \% \mathrm{CI})\end{array}$ & $\begin{array}{l}\text { Cut-off } \\
\text { (ms) }\end{array}$ & $\begin{array}{c}\text { Clinical } \\
\text { value (\%) }\end{array}$ \\
\hline \multicolumn{9}{|l|}{ Prospective studies } \\
\hline Roshanali et al. & 355 & $\begin{array}{l}<1 \text { week prior to } \\
\text { surgery }\end{array}$ & CABG & 19.2 & AEMI & $\mathrm{OR}=1.37(1.20-1.56)$ & $>120$ & $\begin{array}{l}\text { Sensitivity: } 100 \\
\text { Specificity: } 94.8 \\
\text { PPV: } 81.9\end{array}$ \\
\hline Özlü et al. & 128 & NS & CABG & 29.6 & PA-TDI & $H R=1.03(1.02-1.05)$ & $>125.5$ & $N / A$ \\
\hline Muller et al. & 60 & $\begin{array}{l}1 \text { day prior to } \\
\text { surgery }\end{array}$ & CABG/AVR & 38 & PA-TDI & $\mathrm{OR}=7.40(5.90-9.30)$ & $>133$ & $\begin{array}{l}\text { Sensitivity: } 100 \\
\text { Specificity: } 86\end{array}$ \\
\hline \multicolumn{9}{|l|}{ Retrospective studies } \\
\hline Takahashi et al. (2014) & 63 & $\begin{array}{l}<1 \text { month prior to } \\
\text { surgery }\end{array}$ & $A \vee R$ & 65 & PA-TDI & $\mathrm{OR}=1.07(1.02-1.13)$ & $>147.3$ & $\begin{array}{l}\text { Sensitivity: } 77.1 \\
\text { Specificity: } 79.0 \\
\text { PPV: } 79.0\end{array}$ \\
\hline Takahashi et al. (2016) & 73 & $\begin{array}{l}<1 \text { month prior to } \\
\text { surgery }\end{array}$ & MVR/MVP & 60 & PA-TDI & $\mathrm{OR}=1.04(1.01-1.07)$ & $>159.4$ & $\begin{array}{l}\text { Sensitivity: } 55.8 \\
\text { Specificity: } 84.6\end{array}$ \\
\hline Fujiwara et al. & 88 & $\begin{array}{l}<5 \text { days prior to } \\
\text { surgery }\end{array}$ & OPCAB & 39.8 & PA-TDI & $\mathrm{OR}=1.11(1.06-1.16)$ & $>141$ & $\begin{array}{l}\text { Sensitivity: } 74.3 \\
\text { Specificity: } 86.8\end{array}$ \\
\hline
\end{tabular}

Cut-off and clinical values are shown for the electrophysiological parameters obtained from the studies.

$A E M I$, atrial electromechanical interval; AVR, aortic valve replacement; CABG, coronary artery bypass graft; Cl, confidence interval; HR, hazard ratio; ms, milliseconds; MVP, mitral valve plasty; MVR, mitral valve replacement; N/A, not available; NS, not specified; OPCAB, off-pump coronary artery bypass graft; OR, odds ratio; PA-TDI duration, total atrial conduction time; POAF, post-operative atrial fibrillation; TTE, transthoracic echocardiography.

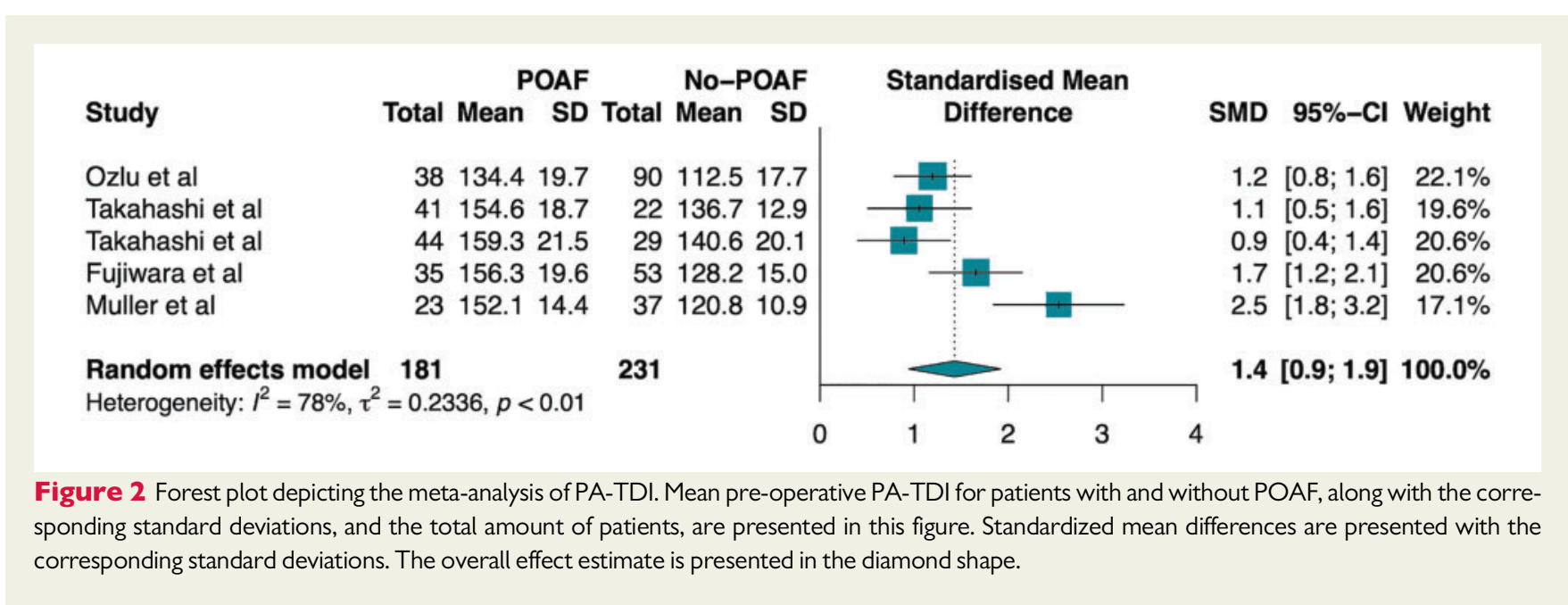

ventricular ejection fraction (LVEF) were independent predictors of POAF. $7,24,27,31-33,37,42,50$ These variables were not assessed in a meta-analysis, since there were no more than five publications reporting them as independent predictors of POAF in multivariable analysis.

Meta-analysis for left atrial volume indexed for body surface

Twenty-seven studies investigated pre-operative left atrial volume indexed for body surface (LAVI) as a potential predictor of POAF
(Table 3). ${ }^{6-11,20-24,38-53}$ Twenty-three studies were included in the continuous variables meta-analysis using random effects model (Figure 3). Four studies were excluded from the meta-analysis because of insufficient data provided in the articles to perform a metaanalysis. $^{43,45-47}$

The cumulative Cohen's $d$ obtained from the meta-analysis was 0.8 (95\% Cl: 0.6-1.0). Figure 5B shows the average LAVI measured in the studies included in the meta-analysis. Average LAVI was higher in patients with POAF as compared to patients without POAF (41.1 vs. 


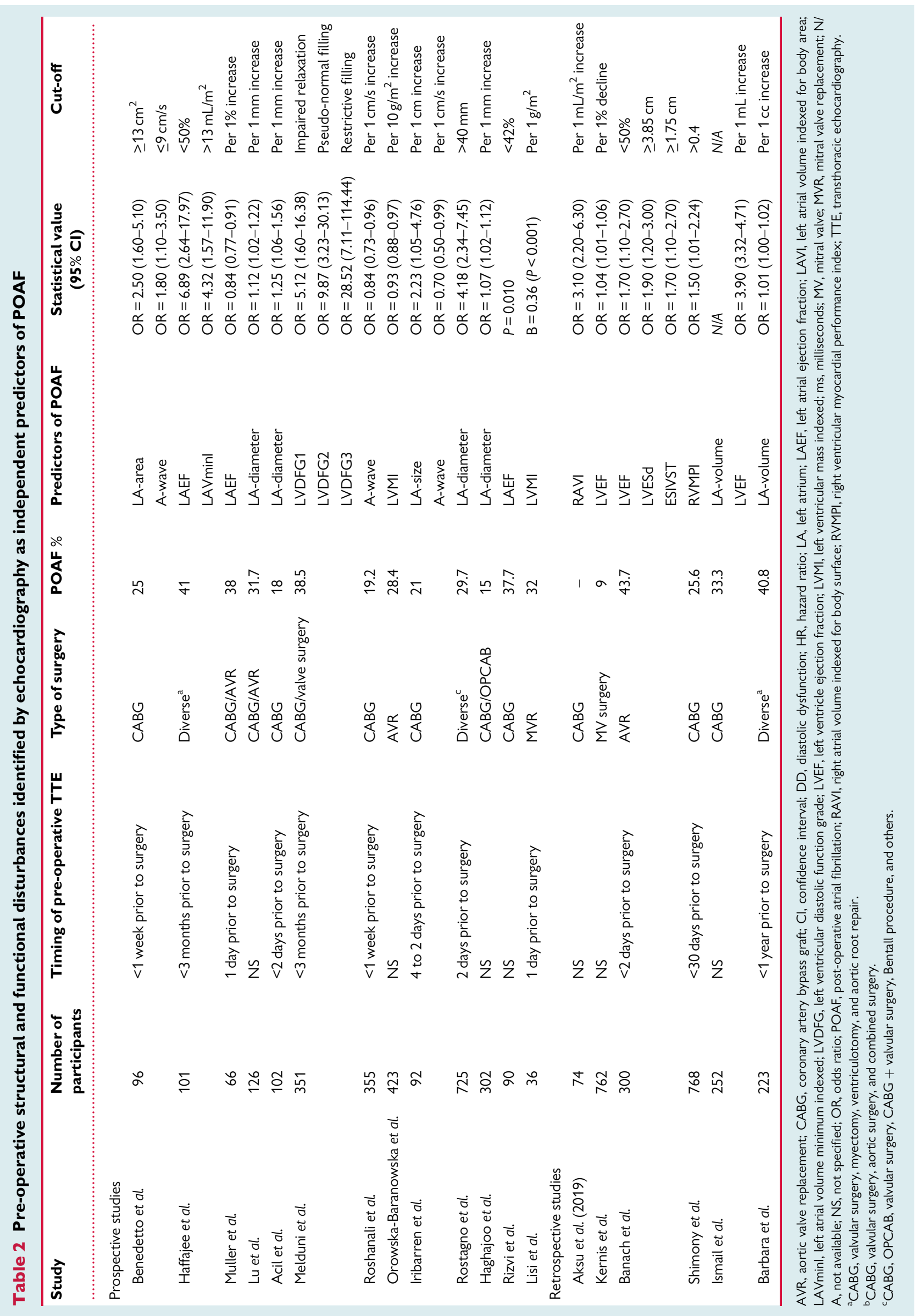




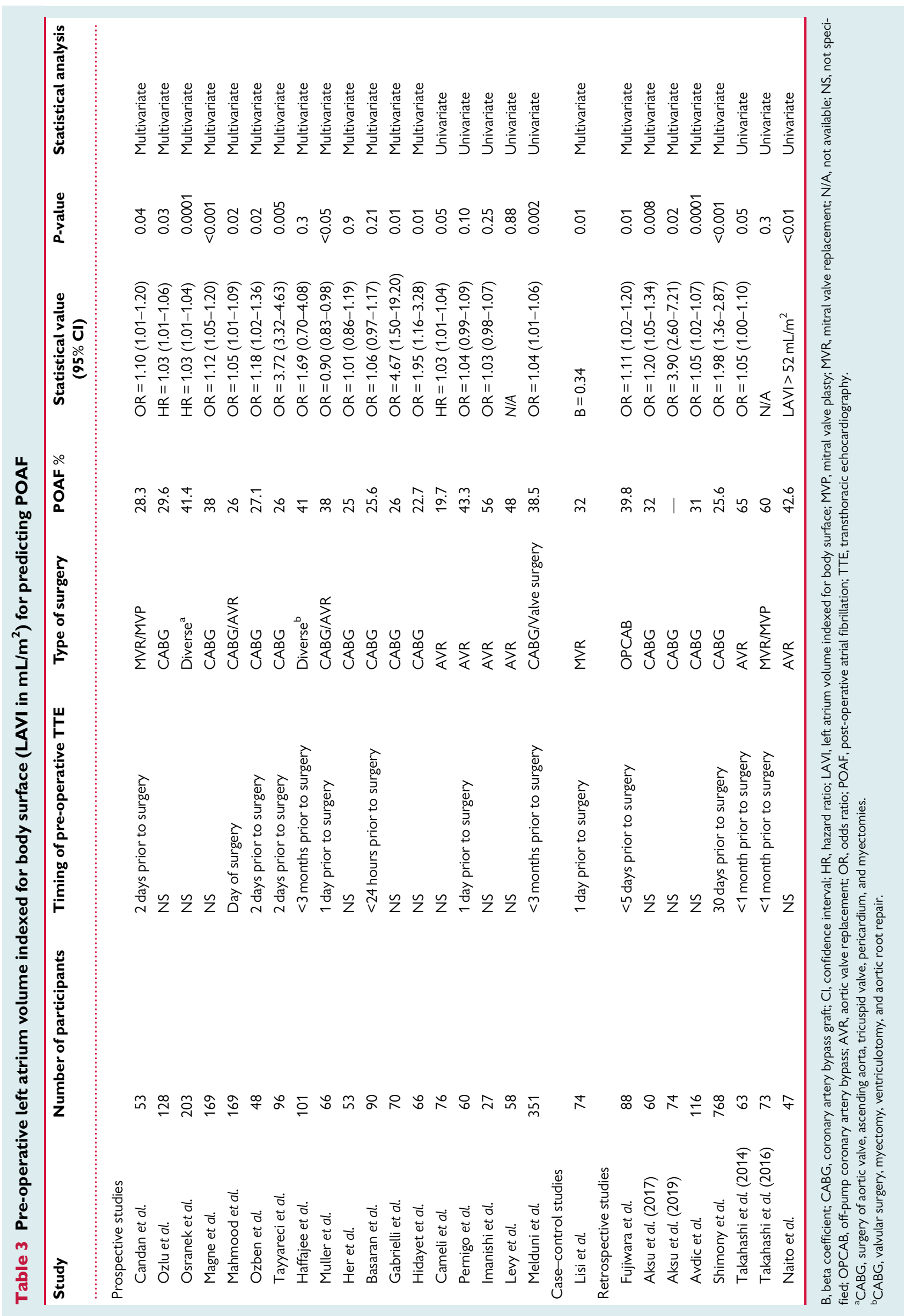




\begin{tabular}{|c|c|c|c|c|c|c|c|c|c|c|}
\hline \multirow[b]{2}{*}{ Study } & \multicolumn{4}{|c|}{ POAF } & \multicolumn{2}{|c|}{ No-POAF } & Standardised Mean & \multirow[b]{2}{*}{ SMD } & \multirow[b]{2}{*}{$95 \%-\mathrm{Cl}$} & \multirow[b]{2}{*}{ Weight } \\
\hline & Total & Mean & SD & Total & Mean & SD & ference & & & \\
\hline Candan et al & 15 & 72.6 & 9.2 & 38 & 52.6 & 14.2 & & 1.5 & {$[0.9 ; 2.2]$} & $3.6 \%$ \\
\hline Ozlu et al & 38 & 30.6 & 11.8 & 90 & 26.1 & 10.1 & & 0.4 & {$[0.0 ; 0.8]$} & $4.9 \%$ \\
\hline Fujiwara et al & 35 & 41.1 & 16.4 & 53 & 31.8 & 10.6 & & 0.7 & {$[0.3 ; 1.1]$} & $4.7^{\circ}$ \\
\hline Melduni et al & 135 & 42.5 & 15.0 & 216 & 34.2 & 12.8 & & 0.6 & {$[0.4 ; 0.8]$} & $5.7^{\circ}$ \\
\hline Osranek et al & 84 & 48.7 & 13.9 & 119 & 39.2 & 16.3 & & 0.6 & {$[0.3 ; 0.9]$} & 5.4 \\
\hline Magne et al & 65 & 38.0 & 11.0 & 104 & 28.6 & 6.0 & & 1.1 & {$[0.8 ; 1.5]$} & 5.2 \\
\hline Mahmood et al & 44 & 37.9 & 15.5 & 125 & 28.6 & 12.3 & & 0.7 & {$[0.4 ; 1.1]$} & 5.1 \\
\hline Ozben et al & 13 & 41.1 & 9.2 & 35 & 32.6 & 9.0 & & 0.9 & {$[0.3 ; 1.6]$} & 3.6 \\
\hline Tayyareci et al & 25 & 35.1 & 6.7 & 71 & 25.8 & 5.9 & & 1.5 & {$[1.0 ; 2.0]$} & 4.3 \\
\hline Gabrielli et al & 18 & 30.0 & 4.0 & 52 & 23.0 & 1.0 & & 3.2 & {$[2.5 ; 4.0]$} & 3.2 \\
\hline Lisi et al & 12 & 66.9 & 25.5 & 25 & 45.1 & 16.1 & & 1.1 & {$[0.4 ; 1.8]$} & 3.3 \\
\hline Shimony et al & 197 & 32.0 & 11.5 & 571 & 28.0 & 11.4 & & 0.4 & {$[0.2 ; 0.5]$} & 5.9 \\
\hline Hidayet et al & 15 & 27.6 & 4.2 & 51 & 20.7 & 4.6 & - & 1.5 & {$[0.9 ; 2.1]$} & 3.7 \\
\hline Takahashi et al (2014) & 41 & 51.0 & 16.8 & 22 & 42.6 & 12.3 & & 0.5 & {$[0.0 ; 1.1]$} & 4.2 \\
\hline Takahashi et al (2016) & 44 & 58.7 & 20.6 & 29 & 53.4 & 16.2 & & 0.3 & {$[-0.2 ; 0.8]$} & 4.5 \\
\hline Muller et al & 23 & 32.8 & 11.5 & 37 & 27.1 & 10.3 & & 0.5 & {$[0.0 ; 1.1]$} & 4.2 \\
\hline Haffajee et al & 41 & 42.5 & 17.7 & 60 & 34.5 & 12.5 & & 0.5 & {$[0.1 ; 0.9]$} & 4.8 \\
\hline Her et al & 13 & 32.6 & 5.1 & 40 & 27.3 & 7.2 & & 0.8 & {$[0.1 ; 1.4]$} & 3.7 \\
\hline Basaran et al & 23 & 34.0 & 11.3 & 67 & 26.4 & 8.4 & & 0.8 & {$[0.3 ; 1.3]$} & 4.4 \\
\hline Cameli et al & 15 & 47.9 & 17.1 & 61 & 41.6 & 15.2 & & 0.4 & {$[-0.2 ; 1.0]$} & 4.0 \\
\hline Pernigo et al & 26 & 42.5 & 14.3 & 34 & 37.2 & 9.8 & & 0.4 & {$[-0.1 ; 1.0]$} & 4.3 \\
\hline Imanishi et al & 15 & 66.0 & 20.0 & 12 & 58.0 & 17.0 & + & 0.4 & {$[-0.3 ; 1.2]$} & 3.1 \\
\hline Levy et al & 28 & 36.0 & 13.0 & 30 & 36.0 & 11.0 & & 0.0 & {$[-0.5 ; 0.5]$} & 4.3 \\
\hline \multirow[t]{3}{*}{ Random effects model } & 965 & & & 1942 & & & & \multirow[t]{3}{*}{0.8} & \multirow[t]{3}{*}[0.6;1.0]{} & 100.0 \\
\hline & $=0.16$ & 620, & 0.01 & & & & 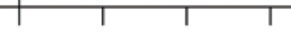 & & & \\
\hline & & & & & & & 3 & & & \\
\hline
\end{tabular}

Figure 3 Forest plot depicting the meta-analysis of LAVI. Mean pre-operative LAVI for patients with and without POAF, along with the corresponding standard deviations, and the total amount of patients, are presented in this figure. Standardized mean differences are presented with the corresponding standard deviations. The overall effect estimate is presented in the diamond shape. LAVI, left atrial volume indexed for body surface; POAF, post-operative atrial fibrillation.

$31.4 \mathrm{~mL} / \mathrm{m}^{2}$, respectively). Studies that included patients with a previous history of paroxysmal AF (PAF) showed a higher LAVI in POAF patients compared to studies excluding PAF patients (46.3 vs. $41.8 \mathrm{~mL} / \mathrm{m}^{2}$, respectively). The overall heterogeneity of the metaanalysis was high $\left(I^{2}=79 \%\right)$. Therefore, a GOSH-analysis was performed to investigate the heterogeneity patterns (Supplementary material online, Figure S2). Three studies were identified as major contributors to the heterogeneity (Supplementary material online, Figures S3-S5). ${ }^{40,41,44}$ After eliminating these studies from the analysis, a sensitivity analysis was performed, which showed that an increased SMD of LAVI was still associated with POAF (Cohen's d of $0.7,95 \%$ $\mathrm{Cl}$ : $0.5-0.8)$ with lower overall heterogeneity $\left(I^{2}=49\right)$ (Supplementary material online, Figure S6).

Subgroup analysis and meta-regression for LAVI

Subgroup analysis and meta-regression were performed for the meta-analysis of LAVI (Table 4). Subgroup analysis on the type of surgery (coronary artery bypass grafting vs. aortic valve replacement vs. diverse vs. mitral valve surgery), \%POAF in the study cohort (>30\% or $<30 \%$ ), pre-operative history of PAF (yes vs. no), and type of study design (prospective, retrospective, or case-control) showed significant differences in the SMD of LAVI. ( $P=0.02,0.03,0.006$, and 0.001 , respectively). Meta-regression showed that cohort age (beta $=$ $-0.04, P=0.01)$ and percentage of male subjects in the study cohort (beta $=0.02, P=0.04$ ) were associated with the SMD of LAVI (Supplementary material online, Figures S7 and S8).

\section{Strain analysis}

Data obtained from the literature on the role of pre-operative strain analysis for predicting POAF are summarized in Table 5. $^{9-12,37,40-}$ $42,47,49,51-55$

\section{Meta-analysis for peak atrial longitudinal strain}

Five studies were included in the continuous variables meta-analysis of peak atrial longitudinal strain (PALS) using a random effects model (Figure 4). ${ }^{10,11,42,49,51}$ One study was omitted from the metaanalysis since there was insufficient data presented in the article. ${ }^{55}$ Figure $5 \mathrm{C}$ demonstrates the cumulative data of all five studies indicating low PALS values in POAF patients as compared to non-POAF patients ( $19.4 \%$ vs. $29.1 \%$, respectively). The cumulative Cohen's $d$ obtained from the meta-analysis was 1.4 (1.0-1.8). The heterogeneity of the model was acceptable at $I^{2}=54 \%$. Furthermore, LV contractile strain, LA contractile 
Table 4 Subgroup analysis and meta-regression for left atrial volume indexed for body surface

\begin{tabular}{|c|c|c|c|c|}
\hline Subgroups & Number of studies & SMD & $95 \% \mathrm{Cl}$ & $P$-value \\
\hline \multicolumn{5}{|l|}{ Study size $(n)$} \\
\hline$<100$ & 16 & 0.90 & $0.57-1.22$ & 0.14 \\
\hline$>100$ & 7 & 0.61 & $0.42-0.81$ & \\
\hline \multicolumn{5}{|l|}{ Type of study } \\
\hline Prospective cohort & 18 & 0.86 & $0.62-1.09$ & 0.001 \\
\hline Retrospective cohort & 4 & 0.39 & $0.25-0.53$ & \\
\hline Case-control study & 1 & 1.12 & $0.38-1.85$ & \\
\hline \multicolumn{5}{|l|}{ Type of surgery } \\
\hline CABG & 10 & 1.09 & $0.68-1.50$ & 0.02 \\
\hline AVR & 5 & 0.35 & $0.10-0.60$ & \\
\hline Diverse $^{\mathrm{a}}$ & 5 & 0.61 & $0.47-0.75$ & \\
\hline Mitral valve & 3 & 0.95 & $0.15-1.75$ & \\
\hline \multicolumn{5}{|l|}{ POAF \% } \\
\hline$<30 \%$ & 11 & 1.06 & $0.67-1.45$ & 0.03 \\
\hline$>30 \%$ & 12 & 0.60 & $0.43-0.76$ & \\
\hline \multicolumn{5}{|l|}{ Definition of POAF } \\
\hline Any duration & 5 & 0.79 & $0.34-1.24$ & 0.17 \\
\hline Any duration + therapy & 3 & 0.43 & $0.26-0.71$ & \\
\hline$>30 \mathrm{~s}$ & 7 & 0.69 & $0.40-0.98$ & \\
\hline At least $>5 \mathrm{~min}$ & 8 & 1.03 & $0.55-1.51$ & \\
\hline \multicolumn{5}{|c|}{ Pre-operative history of paroxysmal AF } \\
\hline No & 17 & 0.92 & $0.67-1.18$ & 0.006 \\
\hline Yes & 6 & 0.47 & $0.28-0.67$ & \\
\hline Meta-regression & Number of studies & Beta & $95 \% \mathrm{Cl}$ & $P$-value \\
\hline Age, per 1 year & 23 & -0.04 & -0.07 to 0.01 & 0.01 \\
\hline Diabetes mellitus, per $1 \%$ & 23 & -0.03 & -0.01 to 0.02 & 0.53 \\
\hline$\%$ Male, per $1 \%$ & 22 & 0.02 & 0.001 to 0.03 & 0.04 \\
\hline Hypertension, per $1 \%$ & 22 & -0.01 & -0.02 to 0.005 & 0.23 \\
\hline BSA, per $1 \mathrm{~m}^{2}$ & 15 & -0.19 & -1.41 to 1.03 & 0.76 \\
\hline LVMi, $g / m^{2}$ & 15 & -0.002 & -0.02 to 0.01 & 0.77 \\
\hline E/e', per 1 unit & 14 & -0.07 & -0.15 to 0.01 & 0.09 \\
\hline BMI, per $1 \mathrm{~kg} / \mathrm{m}^{2}$ & 13 & -0.04 & -0.15 to 0.08 & 0.54 \\
\hline$E / A$, per 1 unit & 9 & -0.23 & -1.34 to 0.88 & 0.68 \\
\hline
\end{tabular}

strain, and LA global longitudinal strain were also impaired in POAF patients. $9,10,12,37,40,41,47,51-55$

\section{Publication bias}

The publication bias of the studies included in the different meta-analyses was explored in funnel plots (Supplementary material online, Figures S9-S11). Egger's test for LAVI showed significant publication bias $(P=0.02)$, whereas PA-TDI and PALS showed no significant publication bias ( $P=0.23$ and 0.45 , respectively). To investigate the actual SMD in face of significant publication bias for LAVI, a trim-and-fill analysis was performed, showing an SMD of 0.5 (0.3-0.7), which might suggest an overestimation of the SMD obtained from the meta-analysis.

\section{Discussion}

This is to our knowledge the first systematic review and meta-analysis of the role of pre-operative TTE in predicting POAF. We found that increased pre-operative TACT (measured as PA-TDI interval), increased LAVI, and reduced PALS have a strong correlation with POAF incidence. These variables depict electrophysiological, structural, and functional cardiac changes associated with an arrhythmogenic substrate for POAF.

\section{Total atrial conduction time}

Intra-atrial conduction delay is one of the characteristics of LA electrical remodelling, resulting in $\mathrm{AF} .^{56} \mathrm{TACT}$, measured as AEMI or PA- 


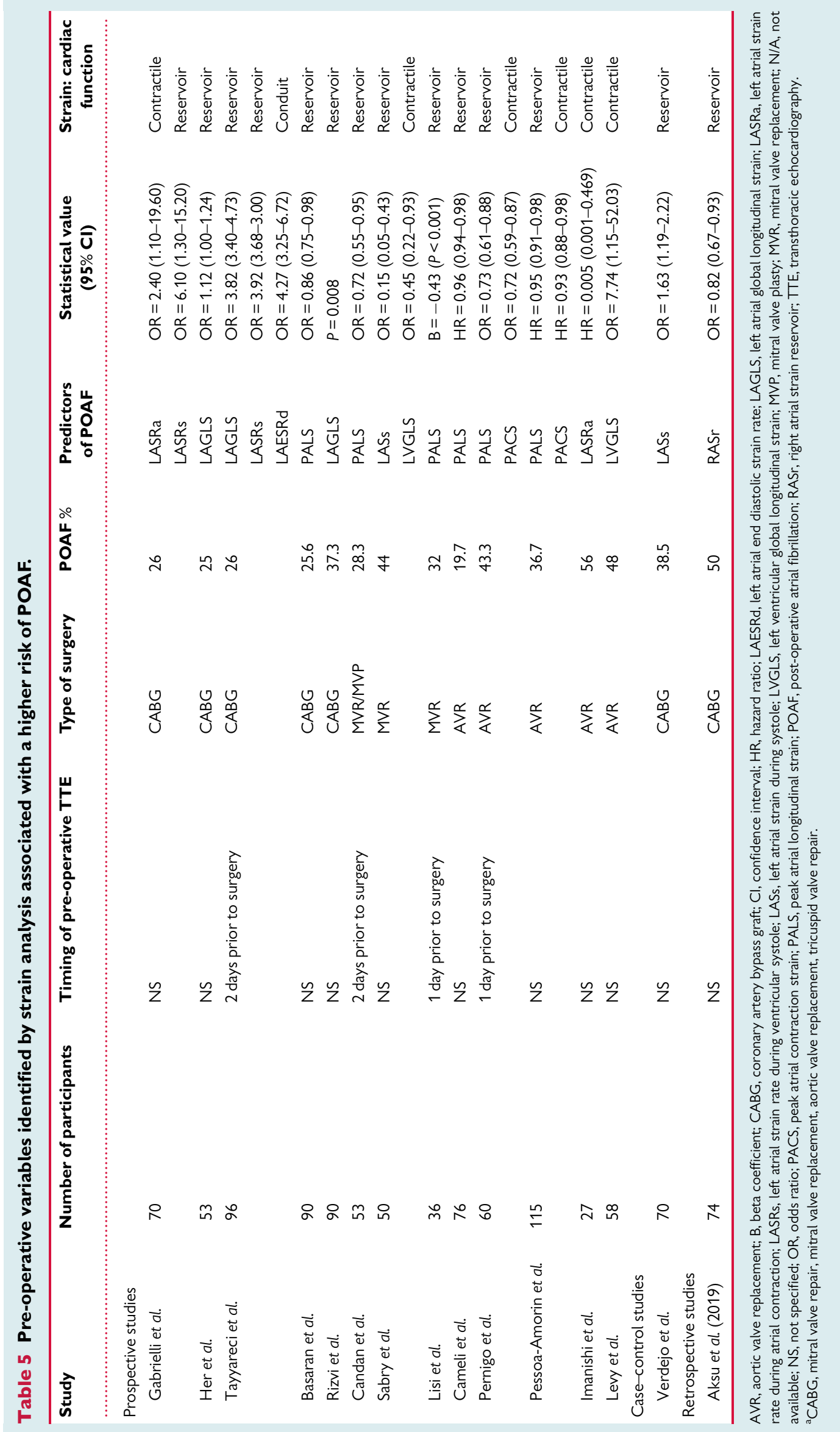




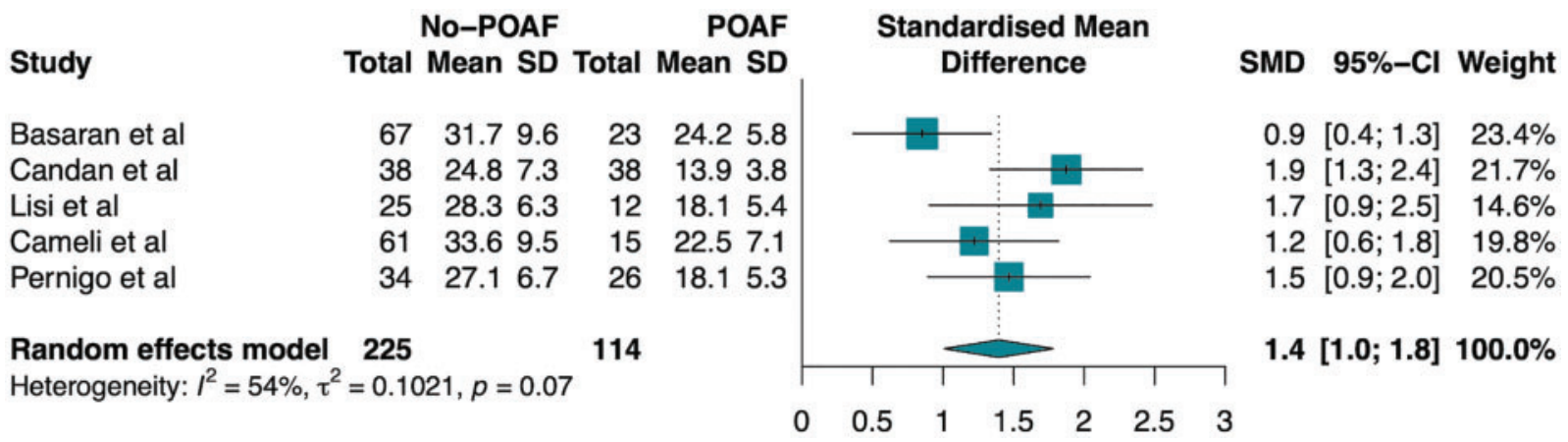

Figure 4 Forest plot depicting the meta-analysis of PALS. Mean pre-operative PALS for patients with and without POAF, along with the corresponding standard deviations, and the total amount of patients, are presented in this figure. Standardized mean differences are presented with the corresponding standard deviations. The overall effect estimate is presented in the diamond shape. PALS, peak atrial longitudinal strain; POAF, postoperative atrial fibrillation.

A

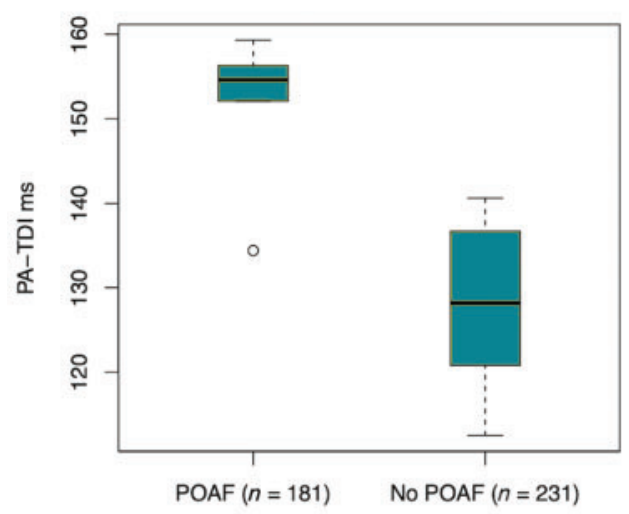

C

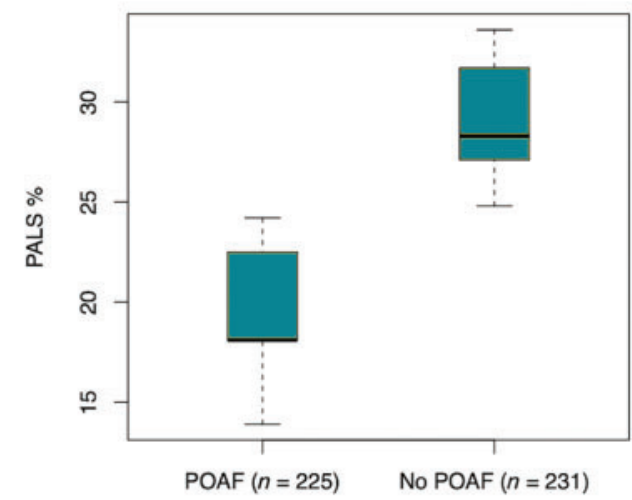

B

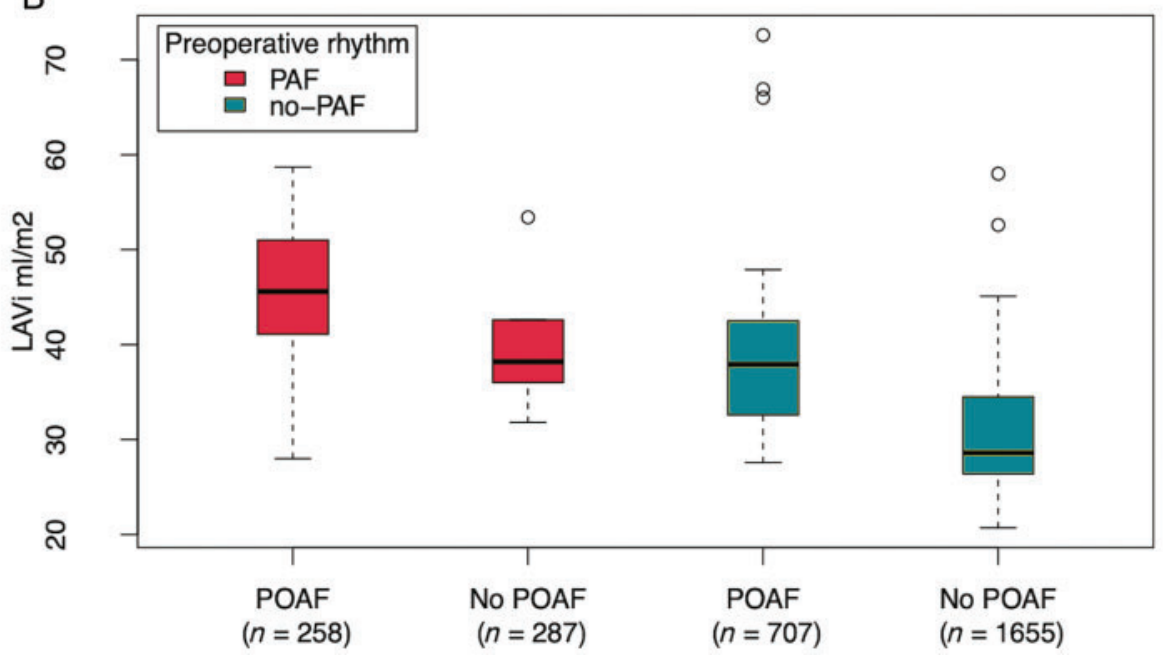

Figure 5 (A) Box plots depicting average difference between pre-operative PA-TDI for patients with POAF and no POAF. (B) Green box plots depict average difference between pre-operative LAVI for patients with POAF and no POAF in studies that excluded patients with history of PAF. Red box plots depict average difference between pre-operative LAVI for patients with POAF and no POAF in studies that included patients with history of PAF. (C) Box plots depicting average difference between pre-operative PALS for patients with POAF and no POAF. LAVI, left atrial volume indexed for body surface; PAF, paroxysmal AF; PALS, peak atrial longitudinal strain; POAF, post-operative atrial fibrillation. 
TDI, is a non-invasive echocardiographic parameter reflecting the intra-atrial conduction delay. PA-TDI was previously validated as a technique for measuring TACT in patients with PAF. ${ }^{57}$ Also, prolonged PA-TDI was linked to hypertension, increased age, diastolic dysfunction, and valvular incompetence in patients with PAF, suggesting a correlation between intra-atrial conduction delays and underlying heart disease. ${ }^{58}$ Our results showed that TACT, measured as AEMI or PA-TDI, is also a useful parameter for identifying patients at risk for POAF. Prolonged pre-operative TACT is most likely the result of LA enlargement and it is associated with significantly higher rates of RA-fibrosis in samples that were obtained during surgery. ${ }^{20,24}$ These structural changes play an important role in creating an arrhythmogenic basis for POAF development through re-entry mechanisms and multiple fibrillation waves in the atria. ${ }^{59}$ Therefore, echocardiographic evaluation of TACT seems to be a promising parameter for detecting both the presence and severity of early electrophysiological changes of the atria predisposing to $\mathrm{POAF}^{20-}$ $25,57,60,61$

\section{Structural and functional parameters}

Structural echocardiographic parameters, such as increased LAV, $L A D$, and LA area, alongside lower LAEF and lower peak atrial systolic mitral annular velocity, were associated with POAF (Table 2). Our meta-analysis showed that patients developing POAF have an increased pre-operative LAVI as compared to patients that post-operatively remain in SR (Figure 3). These variables depict the early structural and functional alterations of the LA that are associated with LA dilatation, most likely caused by myocyte stretching and fibrosis. $^{62}$ LA enlargement is an important predictor of AF development and may be a consequence of volume overload resulting from mitral valve insufficiency or pressure overload due to diastolic dysfunction as a consequence of aortic valve stenosis, hypertension, or ageing. Also, progressive fibrosis of the myocardium causes stiffness of the LV and is responsible for disturbances in the diastolic function of the heart. Higher diastolic filling pressures in the LV increase the pressure in the LA and thereby distension of the pulmonary veins, which at their turn contribute to the arrhythmogenic substrate that is partly responsible for atrial arrhythmias. ${ }^{7}$ In line with this statement, we found that diastolic dysfunction was independently associated with POAF development.

Notably, in the meta-analysis of LAVI, we found significant between-study-heterogeneity, which was further evaluated by subgroup analysis and meta-regression. We could attribute the degree of heterogeneity to differences in major interventions, cohort age, and different comorbidity profiles. Accordingly, we found that studies with older cohorts showed a lower effect size of LAVI suggesting a more complex risk profile of older patients when compared to younger individuals. Also, mean pre-operative LAVI of patients with a history of PAF developing POAF was higher compared to patients with POAF and no history of PAF (Figure 5B). In addition, studies that included patients with PAF were more frequently conducted in patients undergoing aortic or mitral valve surgery, which could explain the increased average LAVI in this population. However, the effect size and mean difference of LAVI appears to be lower in these studies, potentially resulting from pre-existing large atria as a consequence of AF history itself, as compared to studies which excluded patients with a history of AF (Figure 5B).

\section{Strain analysis}

PALS, which is a parameter depicting LA reservoir function, showed a large effect size in the meta-analysis (Figure 4), with an acceptable between-study-heterogeneity. Mean pre-operative PALS was lower in patients with POAF as compared to patients that remained in SR (Figure 5C). Decreased LA strain of the reservoir function depicts the disturbance of the myocardial passive stretching. A possible explanation for these changes is the induction of LA structural remodelling, which is associated with increased myocardial fibrosis and decreased atrial elasticity. ${ }^{56,63}$

Whereas PALS accounts for the amount of overall LA reservoir function, LA strain rate during ventricular systole (LASRs) depicts the velocity of shortening of the myocardial cells, providing information on the elasticity of the atrial wall. ${ }^{40} \mathrm{We}$ found that LASRs was also reduced in patients with POAF, suggesting impaired elasticity of the myocardium. $^{40,41}$ Besides reservoir function abnormalities, pre-operative LA contractile function seems to be impaired in patients that develop POAF. Reduced LA strain rate during atrial contraction (LASRa) and peak atrial contraction strain (PACS) are both associated with POAF, especially in patients with aortic valve stenosis. ${ }^{53}$ These findings suggest that strain analysis is a useful imaging modality for detecting early structural alterations, such as atrial wall stiffness and reduced compliance potentially resulting in a substrate for POAF. ${ }^{64}$

\section{Clinical implications}

Prediction of POAF in a heterogeneous population undergoing cardiac surgery is limited by confounding factors such as type of underlying disease, types of surgery, age of the included population and definition of POAF. Therefore, pre-operative TTE is a promising tool in stratifying substrates in different underlying pathologies. Our meta-analyses show that POAF after cardiac surgery can be predicted by TTE parameters, despite inherently extensive heterogeneity within study populations and potential interobserver variability. Pre-operative electrophysiological disturbances of the atrial myocardium and LA dysfunction provide useful information for pre-operative risk stratification for POAF in patients undergoing cardiac surgery. Echocardiographic parameters depicting these functions are LAVI, PA-TDI interval, and PALS. These parameters indicate pathophysiological changes in the heart, which are associated with susceptibility to POAF, and implementing these measurements in the standard pre-operative care might help to identify patients at risk for POAF. Also, strain analysis provides useful insights into alterations in atrial reservoir, conduit, and contractile function, which are generally overlooked in conventional echocardiography. Furthermore, accurate identification of patients with a substrate for POAF could offer a more targeted deployment of preventive measures, such as preoperative pharmacological prophylaxis or careful fluid balance management in the early post-operative setting. ${ }^{5}$ Also, several studies have demonstrated the positive effect of beta-blockers, antiarrhythmic drugs (for example, sotalol and amiodarone), and magnesium in preventing POAF in the early post-operative phase. ${ }^{5,65}$ Recent studies also showed a reduction in POAF incidence in patients who underwent Calcium-induced autonomic denervation of the major atrial ganglionated plexi or Botulinum toxin injection in epicardial fat pads, during cardiac surgery. ${ }^{66,67}$ Moreover, precise identification of patients at high risk for POAF, based on their substrate, could in the 
future even result in deployment of more rigorous preventive measures, such as pre-emptive AF-ablation during the initial cardiac procedure.

\section{Limitations}

Our meta-analysis is limited, like all meta-analyses, by the quality of the studies included. Since the overall quality of the studies included was high, we believe that the data extracted from the original publications are also of high quality. The included studies showed marked heterogeneity, which was explored by several Influence Analyses (Supplementary material online, Figures S1-S6), and between-study differences, which were explored in several subgroup analyses and meta-regressions. In addition to the inherently heterogeneous population of patients undergoing cardiac surgery, TTE heavily depends on the expertise and experience of the observers. Furthermore, there was significant publication bias present in the meta-analysis for LAVI. The trim-and-fill procedure showed a lack of smaller studies reporting a lower Cohen's $d$ for LAVI. Based on the results from this procedure, we see that the Cohen's $d$ presented in our meta-analysis might be overestimated. Despite these limitations, we found a large effect size in all meta-analyses performed.

\section{Conclusion}

This systematic review of the literature and meta-analysis provides further evidence that a pre-existing substrate predisposes patients to POAF development. We found that pre-operative intra-atrial impulse conduction delays as well as, mostly LA and LV, pre-operative functional impairments, and structural alterations are important echocardiographic variables for predicting POAF. These variables can be effectively measured by conventional bedside TTE and using these parameters should result in a paradigm shift from 'risk-factor-based' predictive models to 'substrate-based' predictive models for POAF.

\section{Supplementary material}

Supplementary material is available at Europace online.

\section{Acknowledgements}

The authors thank Dr Bjorn Winkens (Department of Methodology and Statistics, Maastricht University, Maastricht, The Netherlands) for his insights and advise on the statistical analysis that is presented in the current article.

\section{Conflict of interest: none declared.}

\section{References}

1. Maesen B, Nijs J, Maessen J, Allessie M, Schotten U. Post-operative atrial fibrillation: a maze of mechanisms. Europace 2012;14:159-74.

2. Villareal RP, Hariharan R, Liu B, Kar B, Lee V, Elayda M et al. Postoperative atrial fibrillation and mortality after coronary artery bypass surgery. J Am Coll Cardiol 2004:43:742-8.

3. Ahlsson A, Fengsrud E, Bodin L, Englund A. Postoperative atrial fibrillation in patients undergoing aortocoronary bypass surgery carries an eightfold risk of future atrial fibrillation and a doubled cardiovascular mortality. Eur J Cardiothorac Surg 2010;37:1353-9.

4. Park YM, Cha MS, Park CH, Choi CH, Jeon YB, Kang WH et al. Newly developed post-operative atrial fibrillation is associated with an increased risk of late recurrence of atrial fibrillation in patients who underwent open heart surgery: long-term follow up. Cardiol / 2017;24:633-41.

5. Dobrev D, Aguilar M, Heijman J, Guichard JB, Nattel S. Postoperative atrial fibrillation: mechanisms, manifestations and management. Nat Rev Cardiol 2019;16: 417-36.

6. Osranek M, Fatema K, Qaddoura F, Al-Saileek A, Barnes ME, Bailey KR et al. Left atrial volume predicts the risk of atrial fibrillation after cardiac surgery: a prospective study. J Am Coll Cardiol 2006;48:779-86.

7. Melduni RM, Suri RM, Seward JB, Bailey KR, Ammash NM, Oh JK et al. Diastolic dysfunction in patients undergoing cardiac surgery: a pathophysiological mechanism underlying the initiation of new-onset post-operative atrial fibrillation. J Am Coll Cardiol 2011;58:953-61.

8. Hidayet S, Yağmur J, Bayramoğlu A, Taşolar MH, Kurtoğlu E, Özyalın F. Prediction of postoperative atrial fibrillation with left atrial mechanical functions and NT-pro ANP levels after coronary artery bypass surgery: a three-dimensional echocardiography study. Echocardiography 2018;35:661-6.

9. Her A-Y, Kim J-Y, Kim YH, Choi E-Y, Min P-K, Yoon YW et al. Left atrial strain assessed by speckle tracking imaging is related to new-onset atrial fibrillation after coronary artery bypass grafting. Can J Cardiol 2013;29:377-83.

10. Candan O, Ozdemir N, Aung SM, Dogan C, Karabay CY, Gecmen C et al. Left atrial longitudinal strain parameters predict postoperative persistent atrial fibrillation following mitral valve surgery: a speckle tracking echocardiography study. Echocardiography 2013;30:8.

11. Cameli M, Lisi M, Reccia R, Bennati E, Malandrino A, Solari M et al. Pre-operative left atrial strain predicts post-operative atrial fibrillation in patients undergoing aortic valve replacement for aortic stenosis. Int J Cardiovasc Imaging 2014;30:279-86.

12. Verdejo HE, Becerra E, Zalaquet R, Del Campo A, Garcia L, Troncoso R et al. Atrial function assessed by speckle tracking echocardiography is a good predictor of postoperative atrial fibrillation in elderly patients. Echocardiography 2016;33:242-8.

13. Moher D, Liberati A, Tetzlaff J, Altman DG; PRISMA Group. Preferred reporting items for systematic reviews and meta-analyses: the PRISMA statement. PLoS Med 2009;6:e1000097.

14. Downs S, Black N. The feasibility of creating a checklist for the assessment of the methodological quality both of randomized and non-randomized studies of health care interventions. J Epidemiol Community Health 1998;52:377-84.

15. Olkin I, Dahabreh IJ, Trikalinos TA. GOSH—a graphical display of study heterogeneity. Res Synth Methods 2012;3:214-23.

16. Egger M, Smith GD, Schneider M, Minder C. Bias in meta-analysis detected by a simple, graphical test. BMJ 1997;315:629-34.

17. Duval S, Tweedie R. Trim and fill: a simple funnel-plot-based method of testing and adjusting for publication bias in meta-analysis. Biometrics 2000;56:455-63.

18. R Core Team. R: A Language and Environment for Statistical Computing. Vienna, Austria: R Foundation for Statistical Computing; 2014. www.R-project.org.

19. Schwarzer G, Carpenter JR, RüCker G. Meta-Analysis with R (Use-R!). Switzerland: Springer International Publishing; 2015.

20. Özlü MF, Erdem K, Kırış G, Parlar Ai,, Demirhan A, Ayhan SS et al. Predictive value of total atrial conduction time measured with tissue Doppler imaging for postoperative atrial fibrillation after coronary artery bypass surgery. J Interv Card Electrophysiol 2013;37:27-33.

21. Takahashi S, Fujiwara M, Watadani K, Taguchi T, Katayama K, Takasaki T et al. Preoperative tissue Doppler imaging-derived atrial conduction time can predict postoperative atrial fibrillation in patients undergoing aortic valve replacement for aortic valve stenosis. Circ J 2014;78:2173-81.

22. Takahashi S, Katayama K, Watanabe M, Kodama H, Taguchi T, Kurosaki T et al. Preoperative tissue Doppler imaging-derived atrial conduction time predicts postoperative atrial fibrillation in patients undergoing mitral valve surgery for mitral valve regurgitation. Circ J 2016;80:101-9.

23. Fujiwara M, Nakano Y, Hidaka T, Oda N, Uchimura Y, Sairaku A et al. Prediction of atrial fibrillation after off-pump coronary artery bypass grafting using preoperative total atrial conduction time determined on tissue Doppler imaging. Circ J 2014;78:345-52.

24. Muller P, Hars C, Schiedat F, Bosche LI, Gotzmann M, Strauch J et al. Correlation between total atrial conduction time estimated via tissue Doppler imaging (PATDI Interval), structural atrial remodeling and new-onset of atrial fibrillation after cardiac surgery. J Cardiovasc Electrophysiol 2013;24:626-31.

25. Roshanali F, Mandegar MH, Yousefnia MA, Rayatzadeh H, Alaeddini F, Amouzadeh F. Prediction of atrial fibrillation via atrial electromechanical interval after coronary artery bypass grafting. Circulation 2007;116:2012-7.

26. Barbara D, Rehfeldt K, Pulido J, Li Z, White R, Schaff $H$ et al. Diastolic function and new-onset atrial fibrillation following cardiac surgery. Ann Card Anaesth 2015;18:8-14.

27. Kernis SJ, Nkomo VT, Messika-Zeitoun D, Gersh BJ, Sundt TM, Ballman KV et al. Atrial fibrillation after surgical correction of mitral regurgitation in sinus rhythm: incidence, outcome, and determinants. Circulation 2004;110:2320-5.

28. Acil T, Colkesen Y, Turkoz R, Sezgin AT, Baltali M, Gulcan $O$ et al. Value of preoperative echocardiography in the prediction of postoperative atrial fibrillation following isolated coronary artery bypass grafting. Am J Cardiol 2007; 100:1383-6. 
29. Lu R, Ma N, Jiang Z, Mei J. Hemodynamic parameters predict the risk of atrial fibrillation after cardiac surgery in adults. Clin Cardiol 2017;40:1100-4.

30. Benedetto U, Melina G, Roscitano A, Ciavarella GM, Tonelli E, Sinatra R. Clinical utility of tissue Doppler imaging in prediction of atrial fibrillation after coronary artery bypass grafting. Ann Thorac Surg 2007;83:83-8.

31. Ismail M, El-Mahrouk A, Hamouda T, Radwan H, Haneef A, Jamjoom A. Factors influencing postoperative atrial fibrillation in patients undergoing on-pump coronary artery bypass grafting, single center experience. J Cardiothorac Surg 2017;12:40.

32. Orlowska-Baranowska E, Baranowski R, Michalek P, Hoffman P, Rywik T, Rawczylska-Englert I. Prediction of paroxysmal atrial fibrillation after aortic valve replacement in patients with aortic stenosis: identification of potential risk factors. J Heart Valve Dis 2003;12:136-41.

33. Banach M, Goch A, Misztal M, Rysz J, Jaszewski R, Goch JH. Predictors of paroxysmal atrial fibrillation in patients undergoing aortic valve replacement. J Thorac Cardiovasc Surg 2007;134:1569-76.

34. Iribarren JL, Jiménez JJ, Barragán A, Brouard M, Lacalzada J, Lorente L et al. Left atrial dysfunction and new-onset atrial fibrillation after cardiac surgery. Rev Esp Cardiol 2009;62:774-80.

35. Rostagno C, La Meir M, Gelsomino S, Ghilli L, Rossi A, Carone E et al. Atrial fibrillation after cardiac surgery: incidence, risk factors, and economic burden. J Cardiothorac Vasc Anesth 2010;24:952-8.

36. Haghjoo M, Basiri H, Salek M, Sadr-Ameli MA, Kargar F, Raissi K et al. Predictors of postoperative atrial fibrillation after coronary artery bypass graft surgery. Indian Pacing Electrophysiol J 2008;8:94-101.

37. Rizvi F, Mirza M, Olet S, Albrecht M, Edwards S, Emelyanova L et al. Noninvasive biomarker-based risk stratification for development of new onset atrial fibrillation after coronary artery bypass surgery. Int J Cardiol 2020;307:55-62.

38. Magne J, Salerno B, Mohty D, Serena C, Rolle F, Piccardo A et al. Echocardiography is useful to predict postoperative atrial fibrillation in patients undergoing isolated coronary bypass surgery: a prospective study. Eur Heart J Acute Cardiovasc Care 2019;8:104-13.

39. Ozben B, Akaslan D, Sunbul M, Filinte D, Ak K, Sari I et al. Postoperative atrial fibrillation after coronary artery bypass grafting surgery: a two-dimensional speckle tracking echocardiography study. Heart Lung Circ 2016;25:993-9.

40. Tayyareci Y, Yildirimturk O, Aytekin V, Memic K, Behramoglu F, Demiroglu IC et al. Preoperative left atrial mechanical dysfunction predicts postoperative atrial fibrillation after coronary artery bypass graft operation - a velocity vector imaging-based study. Circ J 2010;74:2109-17.

41. Gabrielli L, Corbalan R, Cordova S, Enriquez A, Mc Nab P, Verdejo HE et al. Left atrial dysfunction is a predictor of postcoronary artery bypass atrial fibrillation: association of left atrial strain and strain rate assessed by speckle tracking. Echocardiography 2011;28:1104-8.

42. Lisi M, Cameli M, Di Tommaso C, Curci V, Reccia R, D’Ascenzi F et al. Mitral regurgitation severity correlates with symptoms and extent of left atrial dysfunction: effect of mitral valve repair. J Clin Ultrasound 2018;46:32-40.

43. Naito Y, Yamazaki K. Preoperative left atrial volume index predicts postoperative atrial fibrillation in patients with severe aortic valve stenosis. J Anesth 2013;27:699-704.

44. Shimony A, Afilalo J, Flynn AW, Langleben D, Agnihotri AK, Morin JF et al. Usefulness of right ventricular dysfunction to predict new-onset atrial fibrillation following coronary artery bypass grafting. Am J Cardiol 2014;113:913-8.

45. Avdic S, Osmanovic E, Kadric N, Mujanovic E, Ibisevic M, Avdic A. Time of occurrence and duration of atrial fibrillation following coronary artery bypass grafting. Med Arch 2016;70:97-100.

46. Aksu U, Gulcu O, Aksakal E, Topcu S, Sevimli S, Tanboga IH. Comparison of the three conventional methods for the postoperative atrial fibrillation prediction. Echocardiography 2017;34:831-4.

47. Aksu U, Kalkan K, Gulcu O, Aksakal E, Ozturk M, Topcu S. The role of the right atrium in development of postoperative atrial fibrillation: a speckle tracking echocardiography study. J Clin Ultrasound 2019;47:470-6.

48. Mahmood E, Khabbaz KR, Bose R, Mitchell J, Zhang Q, Chaudhary O et al. Immediate preoperative transthoracic echocardiography for the prediction of postoperative atrial fibrillation in high-risk cardiac surgery. J Cardiothorac Vasc Anesth 2020;34:719-25.
49. Basaran O, Tigen K, Gozubuyuk G, Dundar C, Guler A, Tasar O et al. Predictive role of left atrial and ventricular mechanical function in postoperative atrial fibrillation: a two-dimensional speckle-tracking echocardiography study. Turk Kardiyol Dern Ars 2016;44:45-52.

50. Haffajee JA, Lee Y, Alsheikh-Ali AA, Kuvin JT, Pandian NG, Patel AR. Pre-operative left atrial mechanical function predicts risk of atrial fibrillation following cardiac surgery. JACC Cardiovasc Imaging 2011;4:833-40.

51. Pernigo M, Benfari G, Geremia G, Noni M, Borio G, Mazzali G et al. Atrial function as an independent predictor of postoperative atrial fibrillation in patients undergoing aortic valve surgery for severe aortic stenosis. J Am Soc Echocardiogr 2017;30:956-65.

52. Imanishi J, Tanaka H, Sawa T, Motoji Y, Miyoshi T, Mochizuki Y et al. Left atrial booster-pump function as a predictive parameter for new-onset postoperative atrial fibrillation in patients with severe aortic stenosis. Int J Cardiovasc Imaging 2014;30:295-304

53. Levy F, Debry N, Labescat AL, Meimoun P, Malaquin D, Marechaux S et al. Echocardiographic prediction of postoperative atrial fibrillation after aortic valve replacement for aortic stenosis: a two-dimensional speckle tracking left ventricular longitudinal strain multicentre pilot study. Arch Cardiovasc Dis 2012;105:499-506.

54. Sabry AM, Mansour HAE, Abo El-Azm TH, Mostafa SA, Zahid BS Echocardiographic predictors of atrial fibrillation after mitral valve replacement. Egypt Heart / 2017;69:281-8.

55. Pessoa-Amorim G, Mancio J, Vouga L, Ribeiro J, Gama V, Bettencourt N et al. Impaired left atrial strain as a predictor of new-onset atrial fibrillation after aortic valve replacement independently of left atrial size. Rev Esp Cardiol (Engl Ed) 2018;71:466-76.

56. Delgado V, Di Biase L, Leung M, Romero J, Tops LF, Casadei B et al. Structure and function of the left atrium and left atrial appendage: AF and stroke implications. J Am Coll Cardiol 2017;70:3157-72.

57. Merckx KL, De Vos CB, Palmans A, Habets J, Cheriex EC, Crijns HJ et al. Atrial activation time determined by transthoracic Doppler tissue imaging can be used as an estimate of the total duration of atrial electrical activation. I Am Soc Echocardiogr 2005;18:940-4.

58. Weijs B, de Vos CB, Tieleman RG, Pisters R, Cheriex EC, Prins MH et al. Clinical and echocardiographic correlates of intra-atrial conduction delay. Europace 2011; 13:1681-7.

59. Lau DH, Linz D, Schotten U, Mahajan R, Sanders P, Kalman JM. Pathophysiology of paroxysmal and persistent atrial fibrillation: rotors, foci and fibrosis. Heart Lung Circ 2017;26:887-93.

60. De Vos CB, Weijs B, Crijns HJGM, Cheriex EC, Palmans A, Habets J et al. Atrial tissue Doppler imaging for prediction of new-onset atrial fibrillation. Heart 2009; 95:835-40

61. Omi W, Nagai H, Takamura M, Okura S, Okajima M, Furusho $\mathrm{H}$ et al. Doppler tissue analysis of atrial electromechanical coupling in paroxysmal atrial fibrillation. J Am Soc Echocardiogr 2005;18:39-44.

62. Thomas L, Abhayaratna WP. Left atrial reverse remodeling: mechanisms, evaluation, and clinical significance. JACC Cardiovasc Imaging 2017;10:65-77.

63. Kuppahally SS, Akoum N, Burgon NS, Badger TJ, Kholmovski EG, Vijayakumar $S$ et al. Left atrial strain and strain rate in patients with paroxysmal and persistent atrial fibrillation: relationship to left atrial structural remodeling detected by delayed-enhancement MRI. Circ Cardiovasc Imaging 2010;3:231-9.

64. Pilichowska-Paszkiet E, Baran J, Sygitowicz G, Sikorska A, Stec S, Kulakowski P et al. Noninvasive assessment of left atrial fibrosis. Correlation between echocardiography, biomarkers, and electroanatomical mapping. Echocardiography 2018;35: 1326-34.

65. Kaireviciute D, Aidietis A, Lip GY. Atrial fibrillation following cardiac surgery: clinical features and preventative strategies. Eur Heart J 2009;30:410-25.

66. Wang $H$, Zhang $Y$, Xin $F$, Jiang $H$, Tao D, Jin $Y$ et al. Calcium-induced autonomic denervation in patients with post-operative atrial fibrillation. J Am Coll Cardiol 2021;77:57-67.

67. Pokushalov E, Kozlov B, Romanov A, Strelnikov A, Bayramova S, Sergeevichev D et al. Botulinum toxin injection in epicardial fat pads can prevent recurrences of atrial fibrillation after cardiac surgery: results of a randomized pilot study. J Am Coll Cardiol 2014;64:628-9. 